\title{
Kan Transfüzyonu ve Reaksiyonları İle İlgili Sağlık Çalışanlarının Bilgi Düzeylerinin Araştırılması
}

\author{
Gülcan TOPAL ${ }^{1}$, İdris ŞAHIN ${ }^{\text {ive }}{ }^{2}$, Emel ÇALIŞKAN ${ }^{2}{ }^{2}$, Özge KILINÇEL ${ }^{3}$
}

ÖZ

Amaç: Kan transfüzyonu, organ nakli gibi önemli bir girişim olarak düşünülmektedir. Kan ve kan ürünleri transfüzyonu hayat kurtarıcı olduğu gibi hata ve ihmal yapılması durumunda ciddi sorunlara, hatta hayatı tehdit edebilecek kayıplara neden olmaktadır. Günümüz modern kan bankacılığında temel kurallardan biri hastaya gereken kan bileşenlerinin güvenli bir şekilde transfüze edilmesinin sağlanmasıdır. Bu çalışma, kan ve kan ürünleri transfüzyonu konusunda hemşirelerin bilgi düzeylerinin belirlenmesi amacıyla yapılmıştır.

Gereç ve Yöntemler: Çalışmamızda, Düzce Üniversitesi Araştırma ve Uygulama Merkezi'nde kan transfüzyonu yapılan kliniklerinde çalışan 100 sağlık personeline 30 sorudan hazırlanmış olan anket uygulaması yapılmıştır. Anket formunda yaş, eğitim durumu, cinsiyet, çalışma süresi, kan transfüzyonuna yönelik hizmet içi eğitim programlarına katılıp katılmadığı gibi kişisel bilgileri içeren altı soru bulunmaktadır. Diğer sorular kan ve kan ürünleri transfüzyonu sonrası bakıma ve komplikasyonlara yönelik bilgileri saptamak amacıyla oluşturulmuştur. Verilerin istatistiksel değerlendirmesinde Ki-kare testi kullanılmıştır.

Bulgular: Çalışmaya katılanların tümü transfüzyon öncesi hasta kan grubu ile ürün kan grubunu ve hasta ismi ile transfüzyon takip formundaki ismin aynı olup olmadığını kontrol ettiğini belirtmiştir. Ayrıca cross-match yapıldığına ve uygunluğuna dikkat ettiğini; transfüzyon öncesi ve sonrasında hastanın vital bulgularına baktığını bildirmiş̧ir. Ankete katılanların \%46'sı kanın koltuk altında ssıtılarak uygulanması gerektiği bilgisine sahiptir. Meslekte 11 yıldan uzun süredir çalışanların transfüzyonla bulaşan enfeksiyonlar konusundaki bilgi düzeyinin, daha kısa süredir çalışanlardan daha yüksek olduğu görülmüştür.

Sonuç: Meslekte daha uzun süredir çalışanların anket sorularına doğru cevap verme oranlarının yüksek olduğu görüldüğü için eğitimlerin sık aralıklarla tekrarlanması gerektiği düşünülmüştür.

Anahtar Kelimeler: Hemşire; kan transfüzyonu; transfüzyon reaksiyonu; transfüzyonla bulaşan enfeksiyon.

\section{Investigation of the Knowledge Levels of Healthcare Professionals about Blood Transfusion and Reactions}

\begin{abstract}
Aim: Blood transfusion is considered to be an important intervention such as organ transplantation. Blood and blood components transfusion is lifesaving; but if mistakes and negligence are made, it causes serious problems and even loss of life threatening. One of the main principles in modern day blood banking is ensuring that blood components that are needed for the patient are safely transfused. This study was conducted to determine the knowledge levels of nurses about blood and blood products transfusion.

Material and Methods: In our study, a questionnaire of 30 questions was made on 100 health personnel working in blood transfusion-applied clinics of Duzce University Research and Application Center. There were six questions including personal information such as age, education level, gender, duration of work, participation in in-service training programs for blood transfusion, in the questionnaire. Other questions were established to determine the information related to care and complications after transfusion of blood and blood components. Chi-square test was used for statistical evaluation of the data.
\end{abstract}

1 Düzce Üniversitesi, Sağlık Bilimleri Enstitüsü, Tıbbi Mikrobiyoloji A.D., Düzce, Türkiye

2 Düzce Üniversitesi, Tıp Fakültesi, Tıbbi Mikrobiyoloji A.D., Düzce, Türkiye

3 Düzce Atatürk Devlet Hastanesi, Tıbbi Mikrobiyoloji Laboratuvarı, Düzce, Türkiye

Sorumlu Yazar / Corresponding Author: Özge KILINÇEL, e-mail: ozgekilincel@gmail.com

Geliş Tarihi / Received: 18.09.2018, Kabul Tarihi / Accepted: 18.10.2018 
Results: All of the participants stated that they checked the patient blood group and component blood group and the name of the patient and the name in the transfusion follow-up form before transfusion. Participants also noted that cross-match was made and paid attention to its suitability; reported that looked at the vital signs of the patients before and after transfusion. Forty-six percent of participants stated that the blood had to be heated underarm. Employees who have been in employment for more than 11 years have been found to be aware of transfusion-transmitted infections at a higher rate than those who work shorter periods.

Conclusion: Since it is seen that those who work longer in the profession have a higher rate of responding correctly to the questionnaire questions; it is thought that the training should be repeated at frequent intervals.

Keywords: Nurse; blood transfusion; transfusion reaction; transfusion-transmitted infection.

\section{GíRiş}

Kan, çeşitli fonksiyonlara sahip çok sayıdaki hücrelerden ve yapılardan oluşan canlı bir doku olarak bilinmektedir. $\mathrm{Bu}$ nedenle kan transfüzyonu da bir doku transplantasyonudur. Akut kanamalar, cerrahi operasyonlar, ciddi kronik hastalık anemilerinde hemoglobin düzeyini artırmak, kanama bozukluklarını düzeltmek gibi birçok kan transfüzyonu endikasyonu bulunmaktadır. Ayrıca kan transfüzyonu uygun şartlar sağlanmadığında hayatı tehdit edici komplikasyonlara neden olabilmektedir $(1,2)$. Hastaya ait kişisel bilgilerin doğru kaydedilmemesi, yanlış tüp kullanılması, kanın 1sıtılma koşullarının uygunsuzluğu, veriliş süresine dikkat edilmemesi, uygunsuz sivilarla birlikte verilmesi gibi hatalı uygulamalar nedeniyle transfüzyona bağlı komplikasyonlar oluşabilmektedir. Özellikle kan ürününün veya hasta kimliğinin yanlış tanımlanması reaksiyonların en önemli nedenleri olarak bilinmektedir (3). $\mathrm{Bu}$ konuda en büyük sorumluluk hemşirelere düşmektedir. Kan transfüzyonu nedeniyle meydana gelen ölümlerin en önemli sebebi \%37'lik oranla ABO kan grubu uyuşmazlığıdır (4-6).

Kan transfüzyonunu uygulayan ve takip eden kişiler hemşireler olduğu için hemşirelerin kan transfüzyonu ve gelişebilecek komplikasyonlar konusunda bilgi düzeylerinin yeterli olması gerekmektedir. Doğru hastaya doğru kanın verilmesi, kanın uygun şekilde bekletilmesi, 1sıtılması, işlem sırasında reaksiyon belirtileri açısından hastanın takip edilmesi, komplikasyon geliştiğinde yapılması gerekenlere hakim olmak hemşirelerin transfüzyon konusundaki sorumluluklarıdır. Bu çalışmada hemşirelerin transfüzyon ve transfüzyonun komplikasyonları hakkında bilgi düzeylerinin araştırılması amaçlanmıştır.

\section{GEREÇ VE YÖNTEMLER}

$\mathrm{Bu}$ çalışmada, Düzce Üniversitesi Araştırma ve Uygulama Merkezi’nde, kan ve kan ürünleri transfüzyonu konusunda bilgi düzeylerinin belirlenmesi amaciyla hemşirelere anket uygulanmıştır. Özellikle kan ve kan ürünü transfüzyonunun daha fazla uygulandığı kliniklerde görev yapan 100 hemşire, ebe ve sağlık memuru çalışmaya dâhil edilmiştir.

Araştırmanın verileri 10.01.2018 - 15.04. 2018 tarihleri arasında 30 sorudan oluşan anket formu kullanılarak hazırlanmıştır. "Kan Transfüzyonu ve Reaksiyonları ile ilgili Sağlık Çalışanlarının Bilgi Düzeylerinin Araştırılması" konulu anket formunda yaş, eğitim durumu, cinsiyet, çalışma süresi ve kan transfüzyonuna yönelik hizmet içi eğitim programlarına katılıp katılmadığı gibi kişisel bilgileri içeren altı soru bulunmaktadır. Diğer sorular kan transfüzyonu ve kan transfüzyonu sonrasındaki bakım ve komplikasyonlara yönelik bilgileri saptamak amacıyla oluşturulmuştur (Ek1).

Çalışma, ilk yazarın yüksek lisans tez çalışmasından üretilmiş olup Düzce Üniversitesi Tıp Fakültesi Klinik Araştırmalar Etik Kurulu'ndan 2015/121 numarası ile kurul onayı alınarak yapılmıştır.

İstatistiksel Analiz

Anket formu ile elde edilen verilerin istatistiksel değerlendirilmesinde SPSS 17 paket programı kullanılmıştır. Kategorik veriler, frekans ve yüzde şeklinde özetlenmiştir. Kategorik özelliklerle kan ürünlerinin 1sıtılma şekilleri, kan ürünlerinin hastaya takılmama sebepleri, kan transfüzyonu ile bulaşabilecek mikroorganizmalar, kan transfüzyonuna bağlı reaksiyon bulgularına verilen cevaplar arasındaki ilişkiler Ki-kare testi (post hoc: Bonferroni testi) ile değerlendirilmiştir.

\section{BULGULAR}

Anket çalışmasına 84'ü kadın, 16'sı erkek olmak üzere 100 sağlık çalışanı katılmıştır. Sağlık çalışanlarının 93'ü hemşire, dördü sağlık memuru, ikisi ebe, biri acil tıp teknisyeni olarak görev yapmakta olduğunu belirtmiştir. Meslekteki çalışma yılları irdelendiğinde; beş yıldan daha kısa süre çalışan sayısı 42, 5-10 yıl arası 18, 11-20 yıl arası 36, 20 yıldan uzun çalışan dört kişi tespit edilmiştir. Ankete katılanların 93'ü kan transfüzyonu konusunda eğitim aldığını, yedisi ise bu konuda eğitim almadığını bildirmiştir. Ankete katılanların tamamı transfüzyon öncesi hasta kan grubu ile ürün kan grubunu ve hasta ismi ile transfüzyon takip formundaki ismin aynı olup olmadığını kontrol ettiğini; cross-match yapılıp yapılmadığına ve uygunluğuna dikkat ettiğini; transfüzyon öncesi ve sonrasında hastanın vital bulgularına baktığını söylemiştir. Serolojik tetkiklerin yapılmış ve negatif olduğunu 12 kişi kontrol etmediğini bildirirken, 11 kişi kan ürünün makroskobisini incelemediğini, iki kişi kan ürünlerinin son kullanma tarihlerine dikkat etmediğini belirtmiştir.

Kan ürünlerinin hastaya takılmama sebeplerinin ne olabileceği sorusuna, 13 kişi soğuk veya sıcak olması, 14 kişi bulanık olması, 12 kişi köpüklü olması, bir kişi pıhtılı olması, üç kişi torba bütünlüğünün bozulmuş olması, 57 kişi ise bunlarının hepsinin kan takılmama sebebi olabileceği şeklinde cevap vermiştir. Kan ürünlerinin hastaya takılmama sebeplerini eksik cevaplayanlarla tam cevaplayan sağlık çalışanlarının sosyodemografik özelliklerine göre dağılımı Tablo1'de gösterilmiştir. 
Tablo 1. Kan ürünlerinin hastaya takılmama sebeplerini eksik cevaplayanlarla tam cevaplayan sağlık çalışanlarının sosyodemografik özelliklerine göre dağılımı

\begin{tabular}{lccc}
\hline \multicolumn{4}{c}{ Kan ürünlerinin hastaya takılmama sebepleri } \\
\hline Sosyodemografik özellik & Eksik cevap verme & Tam cevap verme & p \\
\hline Cinsiyet & & & 0,086 \\
\hline Kadın & $33(\% 39)$ & $51(\% 61)$ & \\
Erkek & $10(\% 63)$ & $6(\% 37)$ & 0,818 \\
\hline Yaş grubu & & & \\
\hline $18-25$ & $16(\% 41)$ & $23(\% 59)$ & \\
$26-35$ & $20(\% 47)$ & $23(\% 53)$ & $\mathbf{0 , 0 1 5 *}$ \\
$>35$ & $7(\% 39)$ & $11(\% 61)$ & \\
\hline Çalışma yılı & & & \\
\hline$<5$ & $19(\% 45)$ & $23(\% 55)$ & \\
$5-10$ & $\mathbf{3 ( \% 1 7 )}$ & $\mathbf{1 5 ( \% 8 3 )}$ & $15(\% 42)$ \\
$11-20$ & $21(\% 58)$ & $4(\% 100)$ & \\
$>20$ & - & $57(\% 57)$ & \\
\hline Toplam & $43(\% 43)$ & & \\
\hline
\end{tabular}

* İstatistiksel analizde ">20 yıldır" çalışanların cevapları hariç tutulmuştur.

Tablo 2. Kan ürününün ısıtılma şeklinin sağlık çalışanlarının sosyodemografik özelliklerine göre dağglımı

\begin{tabular}{|c|c|c|c|c|c|}
\hline \multicolumn{6}{|c|}{ Kan ürününün ssıtılma şekli } \\
\hline $\begin{array}{l}\text { Sosyodemografik } \\
\text { ozzellik }\end{array}$ & $\begin{array}{c}\text { Transfüzyon } \\
\text { merkezinde cihazda }\end{array}$ & Koltuk altında & Sicak suda & Toplam & $\mathbf{p}^{*}$ \\
\hline Cinsiyet & & & & & 0,415 \\
\hline Kadın & $45(\% 54)$ & $37(\% 44)$ & $2(\% 2)$ & $84(\% 100)$ & \\
\hline Erkek & $7(\% 44)$ & $9(\% 56)$ & - & $16(\% 100)$ & \\
\hline Yaş grubu & & & & & 0,080 \\
\hline $18-25$ & $22(\% 56)$ & $17(\% 44)$ & - & $39(\% 100)$ & \\
\hline 26-35 & $17(\% 40)$ & $24(\% 56)$ & $2(\% 4)$ & $43(\% 100)$ & \\
\hline$>35$ & $13(\% 72)$ & $5(\% 28)$ & - & $18(\% 100)$ & \\
\hline Çalışma yılı & & & & & $\mathbf{0 , 0 1 7}$ \\
\hline$<5$ & $28(\% 67)$ & $14(\% 33)$ & - & $42(\% 100)$ & \\
\hline $5-10$ & $8(\% 42)$ & $9(\% 47)$ & $2(\% 11)$ & $19(\% 100)$ & \\
\hline $11-20$ & $12(\% 34)$ & $23(\% 66)$ & - & $35(\% 100)$ & \\
\hline$>20$ & $4(\% 100)$ & - & - & $4(\% 100)$ & \\
\hline Toplam & $52(\% 52)$ & $46(\% 46)$ & $2(\% 2)$ & $100(\% 100)$ & \\
\hline
\end{tabular}

Kan ürünlerinin 1sıtılma şekline verilen cevaplarda yaş grupları ve cinsiyetler arasinda istatistiksel olarak anlamlı fark saptanmamakla birlikte kadınlarda doğru uygulama yüzdesinin erkeklerden fazla olduğu görülmüştür. Ayrıca meslekte 11-20 yıl süredir çalışanlarda doğru uygulama şeklinin anlamlı olarak diğer gruplardan düşük olduğu görülmüştür $(\mathrm{p}<0,05$; Tablo 2$)$.

Kan ürünlerinin veriliş sürelerinin ne olduğunu 83 kişi bildiğini söylemiştir. En çok reaksiyona neden olan kan ürününün 58 kişi tam kan, 36 kişi eritrosit süspansiyonu, altı kişi taze donmuş plazma olduğunu belirtirken; en çok hemolitik reaksiyona neden olan kan ürününün 87 kişi eritrosit süspansiyonu, sekiz kişi taze donmuş plazma, beş kişi trombosit süspansiyonu olduğunu belirtmiştir.

Transfüzyon sırasında reaksiyon geliştiğinde ilk önce ne yaparsınız sorusuna, 89 kişi transfüzyonu hemen durdururum, dokuz kişi hekime haber veririm, iki kişi ise torba ve hasta bilgilerini karşılaştırırım cevabını vermiştir. Hastanın geçmiş transfüzyon reaksiyonlarını sorgulamayı 95 kişi aklına getirdiğini bildirmiştir.
Hangisi kan transfüzyonuna bağlı reaksiyon düşündüren bulgulardandır sorusuna, 25 kişi ateş, 16 kişi şok, sekiz kişi hipotansiyon, beş kişi ajitasyon, dört kişi dispne, iki kişi koyu renk idrar, bir kişi hipertansiyon, 39 kişi ise bu bulguların hepsinin reaksiyon belirtisi olabileceği cevabını vermiştir (Tablo 3).

Kan transfüzyonu ile bulaşabilecek mikroorganizmaların neler olabileceği sorusuna 20 kişi HIV, 13 kişi HBV, 10 kişi HCV olarak cevap verirken, 57 kişi HBV, HCV, HIV ve sifiliz etkeni Treponema pallidum'un hepsinin bulaşabileceğini söyledi. Meslekte 11 yıldan uzun süredir çalışanların transfüzyonla bulaşan enfeksiyonlar konusundaki bilgi düzeyinin \%86 oranla, daha kısa süredir çalışanlardan daha yüksek olduğu görülmüştür $(\mathrm{p}<0,001)$. Ayrıca kadınların 53 (\%63)'ü transfüzyonla bulaşabilecek etkenleri doğru olarak cevaplarken erkeklerde bu oran \%25 (4) olarak saptanmıştır $(\mathrm{p}=0,005)$. 
Tablo 3. Kan transfüzyonuna bağlı reaksiyon bulgularını eksik cevaplayanlarla tam cevaplayan sağlık çalışanlarının sosyodemografik özelliklere göre dağılımı

\begin{tabular}{|c|c|c|c|}
\hline \multicolumn{4}{|c|}{ Kan transfüzyonuna bağlı reaksiyon bulguları } \\
\hline Sosyodemografik özellik & Eksik cevap verme & Tam cevap verme & p değeri \\
\hline Cinsiyet & & & 0,070 \\
\hline Kadın & $48(\% 57)$ & $36(\% 43)$ & \\
\hline Erkek & $13(\% 81)$ & $3(\% 19)$ & \\
\hline Yaş grubu & & & 0,203 \\
\hline $18-25$ & $27(\% 69)$ & $12(\% 31)$ & \\
\hline $26-35$ & $26(\% 61)$ & $17(\% 39)$ & \\
\hline$>35$ & $8(\% 44)$ & $10(\% 56)$ & \\
\hline Çalışma yılı & & & 0,006* \\
\hline$<5$ & $34(\% 81)$ & 8(\%19) & \\
\hline $5-10$ & $8(\% 44)$ & $10(\% 56)$ & \\
\hline $11-20$ & $19(\% 53)$ & $17(\% 47)$ & \\
\hline$>20$ & - & $4(\% 100)$ & \\
\hline Toplam & $61(\% 61)$ & 39 (\%39) & \\
\hline
\end{tabular}

\section{TARTIŞMA}

Kan transfüzyonunun bir doku transplantasyonu olması ve gelişebilecek komplikasyonların da hayati önemi olması nedeniyle uygulamayı yapacak sağlık personelinin bu konuda eğitimli ve bilgi düzeyi yüksek kişilerden oluşması gerekmektedir. Çalışmamızda sağlık personelinin transfüzyon ve olası komplikasyonlar açısından bilgi düzeyleri araştırılmış, cinsiyet, mesleki çalışma süresi gibi sosyodemografik özelliklerine göre bilgi düzeylerindeki değişim incelenmiştir. Araştırmaya katılanların \%93'ünün transfüzyon konusunda eğitim almış olması alınan eğitimin yeterliliğinin tespiti açısından önemlidir.

Karim ve ark. (7)’nın yaptıkları bir çalışmada, 2006-2012 yılları arasında raporlanan 458 transfüzyon reaksiyonunda en yaygın olarak ABO uyumsuzluğu olduğu (\%56), bu uyumsuzluğun da yanlış hasta tanımlamadan kaynaklandığ 1 bildirilmektedir. Rebibo ve ark. (8)'nın yaptıkları çalışmada da, ABO uyuşmazlığı gerçekleşen 12 hastadan dördünün transfüzyon öncesinde hasta başı kimliğinin hatalı tanımlanması sonucunda reaksiyonun geliştiği saptanmıştır. Ülkemizde yapılan bir çalışmada transfüzyon öncesi kontrollere dikkat edildiği tespit edilmiştir (9). Çalışmamıza katılan tüm çalışanların transfüzyon öncesi hasta kan grubu ile ürün kan grubunu ve hasta ismi ile transfüzyon takip formundaki ismin aynı olup olmadığını kontrol ettiklerini; cross-match yapılıp yapılmadığına ve uygunluğuna dikkat ettiklerini; transfüzyon öncesi ve sonrasında hastanın vital bulgularına baktıklarını söyledikleri saptanmıştır. $\mathrm{Bu}$ durum doğru hastaya doğru kan ürününün verilmesi ve transfüzyon öncesi yapılması gereken kontrollerin bilinmesi açısından önemlidir. Hemşirelerin dikkati sayesinde transfüzyon merkezinden gelmiş olabilecek uygunsuz gruptaki kan ürünlerinin hastaya transfüzyonunun önlenebileceği unutulmamalıdır (10).

Transfüzyon öncesi kontrollere dikkat edilmesi ne kadar önemliyse transfüzyon sirasında ve transfüzyon sonrasinda da kurallara uyulması gerekmektedir. Kan ürününün soğuk veya sıcak, bulanık, köpüklü ve pıhtılı olması, torba bütünlüğünün bozulmuş olması durumlarında hastaya transfüzyonun yapılmaması gerekmektedir (11). Ancak çalışmamıza katılanların \%43’ü bu durumların hepsinin değil bazılarının kan ürünü takılmaması sebebi olabileceğini söylemişlerdir. Meslekte 5 ila 10 yıl arası çalışanların kan ürünü takılmama sebeplerini tam olarak bilme oranının (\%83), 11 ila 20 yıl arası çalışanlardan (\%42) anlamlı olarak daha yüksek olduğu görülmüştür $(\mathrm{p}=0,015)$. Bu nedenle konuyla ilgili eğitimlerin sıklaştırılması ve belirli aralıklarla çalışanların bilgi düzeylerinin değerlendirilmesi gerektiği düşünülmüştür.

Transfüzyon öncesi kan ve kan ürünlerinin uygun ısıya getirilmesi ve bunun için uygulanacak yöntem oldukça önemlidir. Erkoç (12) tarafından yapılan çalışmada bu konu ile ilgili soruya hemşirelerin \%75,5'inin doğru cevap verdiği saptanırken, hemşirelerin kanı uygun ısıya getirmek için kullanılacak uygun yöntemleri yeterince bilmediğinin görüldüğü çalışmalar da bulunmaktadır $(3,9,13)$. Çalışmamızda kan ürünlerini uygun 1sıya getirmek için kullanılması gereken yöntemi çalışmaya katılanların \%48'i yanlış cevaplamıştır. \%46 oranında "koltuk altında 1sitma uygun yöntemdir" cevabının verilmiş olması eğitim alma oranının \%93 olduğu bu grupta eğitimin yetersizliğini düşündürtmüştür. 11 ila 20 yıldır görevde olanların \%63 oranında bu soruyu yanlış cevaplamış olmaları meslekte daha uzun süre tecrübesi olanların yeni yöntemleri takip etmediklerini göstermiştir. Kan transfüzyonu nedeniyle meydana gelebilecek reaksiyonlar ölümcül ya da hayat kalitesini önemli oranda etkileyecek hastalıklara neden olabilmektedir. Bu nedenle transfüzyonu uygulayan sağlık personelinin reaksiyonlar konusunda her türlü bilgi ve donanıma sahip kişiler olması sağlanmalıdır (4). Reaksiyon tipine göre ortaya çıkabilecek bulgular da farklı olabilmektedir. Ancak sıklıkla ateş, titreme, bulantı, kusma, taşikardi, solunum sıkıntısı, bel ağrısı, göğüs ağrısı, ürtiker, kanın verildiği ven boyunca kızarıklık ve yanma, baş ağrısı, baş dönmesi, hipotansiyon ve hematüri ortak bulgular arasında sayılabilmektedir (6). Sağlık çalışanlarının bu bulguları biliyor ve takip ediyor olması ile hastalar ölümcül reaksiyonlardan kurtarılabilmektedir. Güleryüz (14) çalışmasında reaksiyon belirtilerini hemşirelerin \%26,19'unun doğru cevapladığını bildirmiştir. Şahin (9) tarafından yapılan çalışmada da transfüzyon reaksiyon belirtilerini bilen hemşirelerin oranı çalışmamızla benzer 
şekilde \%50'den daha az saptanmıştır. Çalışmamıza katılanların \%61'i reaksiyonlarla ilgili eksik cevap vermiştir. Yine istatistiksel olarak fark olmamakla birlikte erkeklerde soruya tam cevap verme yüzdesinin kadınlardan oldukça düşük olduğu saptanmıştır. Meslekte beş yıldan kısa süredir çalışanlarda eksik cevap verme oranının daha uzun süredir çalışanlardan anlamlı şekilde yüksek olduğu tespit edilmiştir. Reaksiyon belirtilerini meslekte tecrübesi daha fazla olanların daha iyi bildikleri görülmektedir.

Kan ve kan ürünleri ile bulaşan mikroorganizmaların sayısı oldukça fazla olmakla birlikte ülkemizde görülme sıklığı ve hastalığın ciddiyeti nedeniyle HBV, HCV, HIV ve sifiliz için tarama testleri yasal olarak zorunludur (2). $\mathrm{Bu}$ etkenlerin kan transfüzyonu ile bulaşabileceğini bilmek alınacak önlemler açısından önemlidir. Güleryüz (14) çalışmasında hemşirelerin \%80,16'sının konu ile ilgili soruyu doğru cevapladığını bildirmiştir. Şahin (9) tarafından yapılan çalışmada ise bu konuyla ilgili sorulan soruya hemşirelerin hiçbirinin doğru cevap vermediği görülmüştür. Çalışmamıza katılanların \%43'ü bu etkenlerin hepsinin transfüzyonla bulaşabileceğini bilmemekteydi. Bu nedenle transfüzyonla bulaşabilecek enfeksiyonlar konusunda çalışanlara eğitimlerin daha sık aralıklarla düzenlenmesi gerektiği düşünülmüştür.

\section{SONUÇ}

Kan transfüzyonunu uygulayan ve takip eden kişiler hemşireler olduğu için hemşirelerin kan transfüzyonu ve gelişebilecek komplikasyonlar konusunda bilgi düzeylerinin yeterli olması önemlidir. $\mathrm{Bu}$ nedenle hemşirelerin eğitimlerinin ve bilgi düzeyi ölçümlerinin sık aralıklarla tekrarlanması gerekmektedir.

\section{KAYNAKLAR}

1. McCelland DBL. Handbook of transfusion medicine. 4th ed. London: TSO; 2007.

2. Türkiye Kan Merkezleri ve Transfüzyon Derneği. Ulusal Kan ve Kan Ürünleri Rehberi. İstanbul: Çesa Basim Hizmetleri; 2011.

3. Whitehead S, Kenny-Siddique S, Scott Y, Parker PI, Hardy J, Wallis JM. 'Tag and label' system for checking and recording of blood transfusion. Transfus Med. 2003; 13(4): 197-203.

4. Williamson LM, Lowe S, Lowe EM, Cohen H, Soldan K, McClelland DB, et al. Serious hazards of transfusion (SHOT) initiative: Analysis of the first two annual reports. BMJ. 1999; 319(7201): 16-9.

5. Chiaroni J, Legrand D, Dettori I, Ferrera V. Analysis of ABO discrepancies occurring in 35 French Hospitals. Transfusion. 2004; 44(6): 860-4. doi: 10.1111/j.1537-2995.2004.03337.x.

6. Linden VJ, Wagner K, Voytovich AE, Sheehan J. Transfusion errors in New York State: An analysis of 10 years' experience. Transfusion. 2000; 40(10): 1207-13.

7. Karim F, Moiz B, Shamsuddin N, Naz S, Khurshid M. Root cause analysis of non-infectious transfusion complications and the lessons learnt. Transfus Apher Sci. 2014; 50(1): 111-7. doi: 10.1016/j.transci.2013.10.004.

8. Rebibo D, Hauser L, Slimani A, Herve P, Andreu G. The French haemovigilance system: Organization and results for 2003. Transfus Apher Sci. 2004; 31(2): 145-53. doi: 10.1016/j.transci.2004.07.010.

9. Şahin H. Hemşirelerin kan transfüzyonlarına yönelik bilgi düzeyleri ve buna eğitimin etkisi [Yüksek Lisans Tezi]. Afyonkarahisar: Afyon Kocatepe Üniversitesi Sağlık Bilimleri Enstitüsü; 2006.

10. Andreu G, Morel P, Forestier F, Debeir J, Rebibo D, Janvier G, et al. Hemovigilance network in France: Organization and analysis of immediate transfusion incident reports from 1994 to 1998. Transfusion. 2002; 42(10): 1356-64.

11. Özata M, Altunkan H. Hastanelerde tıbbi hata görülme sıklıkları, tıbbi hata türleri ve tıbbi hata nedenlerinin belirlenmesi: Konya örneği. Tip Araştırmaları Dergisi. 2010; 8(2): 100-11.

12. Erkoç D. Kuzey Kıbrıs Türk Cumhuriyeti'nde Bir Devlet Hastanesindeki Kan Transfüzyon Sürecinin İyileştirilmesi [Yüksek Lisans Tezi]. İzmir: Dokuz Eylül Üniversitesi Sağlık Bilimleri Enstitüsü; 2010.

13. Göktaş Baltacı S, Yıldız T, Koşucu SN, Urcanoğlu ÖB. Kan Transfüzyonunda hemşirelik uygulamalarının değerlendirilmesi. IAAOJ Health Science. 2015; 3(2): 10-20.

14. Güleryüz MA. Kan ve kan ürünleri transfüzyonu konusunda hemşirelerin bilgi düzeyinin belirlenmesi [Yüksek Lisans Tezi]. Lefkoşa: Yakın Doğu Üniversitesi Sağlık Bilimleri Enstitüsü; 2015. 